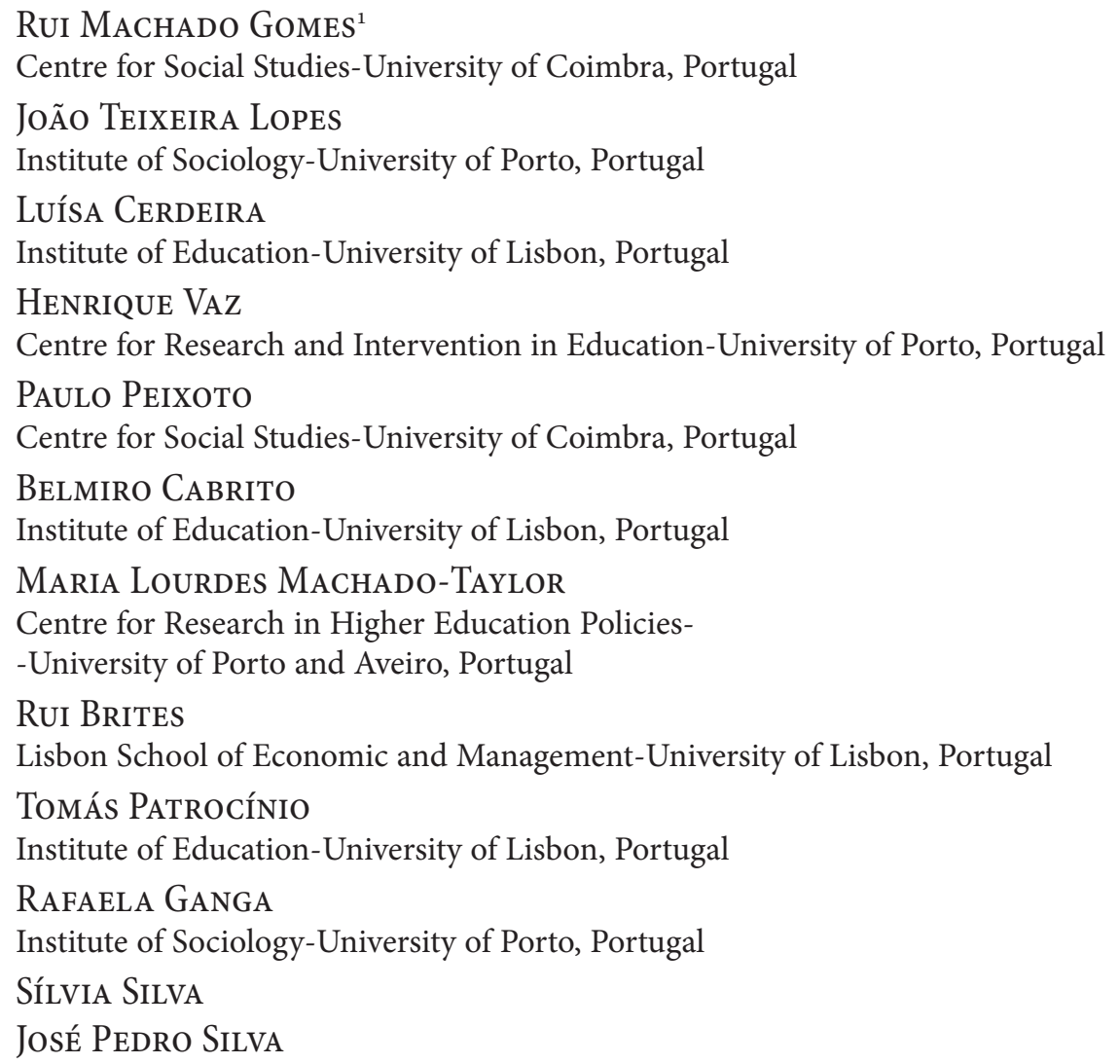

\title{
Asymmetric Mobility and Emigration of Highly Skilled Workers in Europe: The Portuguese case
}

Emigration is a chronic structural process of the Portuguese society. The discussion and key arguments raised in this chapter are mainly focused on data from a research project on

${ }^{1}$ Corresponding author: Rui Gomes: ramgomes@gmail.com 
Portuguese skilled emigration. Based on the outcomes of the BRADRAMO ${ }^{2}$ on-line survey to 1011 highly skilled emigrants it can be suggested that recent phenomena in general, and the crisis that began around 2008 in particular, profoundly transformed the patterns of Portuguese emigration. Nowadays, the country faces a brain drain dynamic that is dramatically altering the profiles of national emigrants, emigration destinations, self-identity, and the strategies of those who leave the country. Academic mobility, mainly that promoted by the European Union (through grants from the Erasmus Program), created and fostered mobility flows that reinforced a latent mobility phenomenon. Once engaged in academic mobility programs, Portuguese higher education students tend to stay in the country of destination or, upon returning temporarily to Portugal, to evince a very strong predisposition to move to a country of the European Union. The profile of Portuguese high-skilled emigrants reveals a trend towards a permanent and a long-term (as opposed to a temporary or transitory) mobility, an insertion in the primary segment of the labor market of the destination countries, a predominance of professionals connected to the academic/scientific system and to professions requiring high skills, and a latent mobility (after a period of study in the country of destination) rather than direct mobility flows (after having entered in the employment system of the sending country).

Keywords: Brain Drain, Brain Circulation, Academic Mobility, Deskilling, Reskilling.

\section{State of the Art}

Emigration of highly-skilled professionals from less developed countries to developed countries leaves the sending countries' economies with a reduced supply of skilled people in research, production, and in public and private services. Skilled emigration has been analysed according to two contrasting models: a) the model of the exodus that stresses the idea that more skilled individuals are forced to the exile, allowing them to get a job and a remuneration corresponding to their training; b) the model of the Diaspora that stresses the mutual benefits of intercultural exchanges opened by the circulation of academic, scientific and cultural cosmopolitan elites.

This research intended to test the comprehensive power of each of these theses referencing to the various types of mobility of highly qualified Portuguese professionals to Europe in the last decade. Although the existing statistics are poor on the methodology used and limited in its scope, it is recognized in international studies published over the past years that Portugal is one of the European countries where the drain is more accentuated in the last decade. Docquier and Marfouk (2007) estimated at $19.5 \%$ the proportion of workers with higher academic degree who emigrated in recent years.

2 BRADRAMO - Brain Drain and Academic Mobility from Portugal to Europe (PTDC/IVC-PEC/5040/2012). Project financed by the Portuguese Foundation for Science and Technology, FCT (Fundação para a Ciência e Tecnologia) e COMPETE. This paper is also supported by the Portuguese Foundation for Science and Technology, FCT, under the Strategic Project UID/SOC/50012/2013. See more in Gomes 2015a, 2015b and www.bradramo.pt. 
Our hypothesis consist in assuming that the different migration flows as well as the contexts, projects, the paths of life and how biographical expectations are constructed and therefore can be understood by the concurrent models. The literature identifies five main theoretical models with different levels of empirical evidence.

The model of brain drain: since human capital is not made profitable in the same society or country where it was generated there is a loss of capital invested in the training of these individuals and, therefore, a potential loss of externalities that result from this investment in the medium and long term. There is evidence of negative effects on economic growth and human capital training in the country of origin (Miyagiwa 1991; Haque and Kim 1995). Thus the return of the educational investment can be loosed by the effect of emigration of human resources, measured through the return losses of capital or through loss development potential (Rosenbaum et al. 1990). The brain drain results in a subsidy to the rich countries (Hamilton 2003) because the growth of most developed countries also stems from the concentration of human capital (Castles and Miller 2003).

The model of a beneficial brain drain: since the emigration of skilled individuals results in higher individual income and this is made possible through their investment in education, then more individuals will be available to invest in their education and their children education and this will eventually increase the return rate to education in developing countries (Mountford 1997). The results from this type of analysis are mixed. Some empirical studies proxying investments in human capital by the growth rate of the proportion of tertiary educated individuals find that the brain drain rate measured in the base period exerts a positive effect on the rate of change of the previous stock of human capital, interpreted as a brain gain (Beine, Docquier, and Rapoport 2003, 2008; Docquier, Faye, and Pestieau 2008). On the contrary, Heuer (2011) modeling anticipatory expectation-building and accounting for possible convergence forces in the accumulation process of human capital, reveal a strong negative effect of the occupation specific emigration rates on the sending countries employment shares, which suggests an inexistent brain gain compared to the brain drain.

The model of the cross fertilization movement of elites: since the international mobility of skilled human resources is often transitory and takes on characteristics of exchange of knowledge, skills, and temporary projects, this circular process is beneficial for both developed countries and developing countries. Olesen (2002), criticizing the study of short-term impacts of brain drain, says that the benefit to the country of origin may occur in the medium term. The highly skilled emigrants who leave their countries of origin for more than 10 years send savings while abroad and transfer human capital, financial and social when return, beating the immediate negative effects. Faini (2003) instead concludes that the qualified emigration provides remittance flows for instance reducing the financial return. Moreover qualified mobility can occur regardless of salary benefits obtained (Mahroum 2000). 
For these groups the economic motives represent only a part of the reason for migration, and may even be accompanied by negative economic effects (Forster 2000).

The model of brain circulation by creating networks: as scientific and business transnationalism results in networking in order to transfer technology and knowledge from the host countries to the countries of origin, it is expected that the increase in the circulation of knowledge and people in the context of globalization is inevitable, regardless of the level of development of countries of origin. The temporary movement of highly qualified individuals appears to complement with increasing frequency the long-term migration, especially among industrialized countries (Straubhaar 2000). The networks formed by scientific diasporas and business have frequently sought to use the knowledge and skills acquired by scientists and other expatriate professionals in the development of the country of origin (Meyer 2001).

The model of latent brain drain due to the mobility training: as mobility training, or for graduate studies or post-graduates, worsened in the last decade, the outputs to study abroad, with or without grants, originally planned as temporary, may become permanent due to the insertion in the labor market of developed countries or less affected by unemployment of young workers (Pizarro 2005). However, there is also evidence that a period of study abroad, followed by a work experience in the destination country can become a medium-term benefit on the return (Johnson and Regets 1998).

The literature review allows us to conclude that the traditional perception of the brain drain has no empirical evidence on the aggregate level, being necessary the understanding of the circumstances and factors that influence the process in each country (Beine, Docquier, and Rapoport 2003). This research aims to make a pioneering study of this type in the Portuguese context, still innovating in conceptual and methodological terms: first, refusing the logic of globalizing assumptions of human capital theory, guessing that migration can be caused by factors other than not pay gap by analyzing the set of factors of attraction-repulsion; on the other hand, guessing that the international job system is not only dependent on the free play of supply and demand, it is also necessary to observe the biographical trajectories in order to understand the reasons and destinations of migration.

\section{Methodology}

Being the brain drain a multifaceted phenomenon, the research design follows the relational nature of the social object, articulating many dimensions of analysis. From the comparative study of four cases representing different profiles of highly 
skilled emigration, the study will involve the understanding of each case, and, at the same time, will seek to deliver factors and processes of comparison, translation and transfer.

The selection of the four cases will follow the intersection of the main structuring principles shown in the most significant empirical research:

- Time characteristics of mobility: permanent or temporary; long term or transitory.

- Social place in the employment system: primary segment or secondary segment of the system;

- Functional profile in the employment system: academic and scientist; other highly skilled professions;

- Type of mobility: direct (after having entered in the employment system of the sending country); indirect or latent (after a period of study in the receiving country).

The four case studies describe and compare the circumstances, modalities and characteristics of European mobility flows of highly qualified subjects: i) migration to a European country to work in the scientific or higher education system; ii) longterm migration to a European country to work in the primary or secondary sectors of the employment system; iii) European student mobility leading to integration in the primary or secondary sectors of the employment system; iv) temporary or transitory mobility and circulation in the European networks of science, production, services or culture.

In each case, we have begun with focus groups in the different cases under analysis. Taking advantage of the intersubjective and shared nature of this technique (Krueger 1998), we believed that prior to the application of the survey, it will be particularly useful to identify push and pull factors and deskilling and reskilling factors, because the review of the state-of-the-art points to very general factors. In this way, the dimensions and indicators of the survey will be more accurate.

To this extent, the questionnaire ${ }^{3}$ deliberately chooses a dominant audience with high academic skills -, but must contain the many situations expressed in the study cases to be developed, which, in a way, determines a prior categorization likely to ensure comparability with the survey instrument, a comparability that allows us to discriminate determining traits in the characterization of the phenomenon. Accordingly, the structure of the questionnaire, in addition to the independent variables that characterize the target population, seek to list a set of scales covering the following topics:

${ }^{3}$ A directly printed version of the BRADRAMO online survey can be accessed at the following link: http://www.bradramo.pt/wp-content/uploads/2015/10/Surveys@UC-Bradramo_V.Impressao.pdf 
1) Push and pull factors: these two entries will distinguish, to begin with, the types of migration, including the ability to determine an idea and a plan; the access to information that supports such plan; the networks of relationships in the decision to migrate; the role of employer institutions, potential or identified (in the country of origin and country of destination); identification (or not) of a migratory chain.

2) Factors perceived as crucial in the decision to migrate: to conceive a future in which migration is an option may be determined by various factors, starting henceforth with the economic crisis; the devaluation of local resources (versus their higher value in the desired destination); the lack of career opportunities (versus more opportunities to build a career in the desired destination); unemployment (versus more jobs in the desired destination); etc.

3) Deskilling and reskilling: the decision behind migratory flows may reflect the notion of deskilling underlying a professional practice not based on the skills held, or, conversely, the possibility that the desired (or held) destination will enhance those skills, in a process of reskilling.

4) Brain gain and brain waste: the ties that migrants have with their country of origin, including ties with the contexts of production that best articulate their areas of knowledge/reliability may help understand if migratory movements contribute more to situations of brain gain- a situation that offers employability and remuneration not likely to be obtained in the country of origin - or to situations of brain waste - in which migration to a context with high intellectual standards may result in outsourcing that requires less skills than those held.

5) Social and cultural mobility: another decisive aspect in understanding migratory flows, and in particular those that refer to highly skilled populations, is the decision to stay for a longer or shorter period of time, and also the impact that the intersection of cultural and social aspects may have in perceiving globalization. It is important to understand to what extent the decision to migrate based, at its outset, on training and employment reasons becomes (or not) social mobility, and cultural mobility.

\section{Questionnaire}

This project tells the stories of individual Portuguese men and women who have decided to carry on their lives out of Portugal. Singular stories, however, are set in a more general social framework. Individual paths materialise under conditions that were not chosen but were rather the starting point for each individual's options. In fact, the decision to migrate involves structural features corresponding to the external form of the phenomenon that limit or enlarge the effects of individual decisions. 
Those structural conditions were characterised through an on-line survey-questionnaire answered between May and October 2014 by an intentional non random sample of 1011 Portuguese citizens who were or had been on mobility, or were or had been immigrants in a European country over the last six years; had higher education qualifications; or had worked in positions compatible with higher education level. The Portuguese qualified emigration was structurally profiled based on the answers to this questionnaire, and using statistical data from the Emigration Observatory [Observatório da Emigração] (2014), from Pordata, from OECD, and from ONS (Office for National Statistics, UK).

Data is presented in the question-answer format.

\subsection{How many are they?}

According to the data provided by the Emigration Observatory [Observatório da Emigração] (2014), the emigration of qualified Portuguese has had an $87.5 \%$ growth between $2000 / 1$ and $2010 / 11$, from a relative value of $6.2 \%$ of total emigration to a value of $9.9 \%$ in $2010 / 11$, now accounting for $11 \%$ of total emigration. Based on the latter value, the qualified emigration flow is estimated to have reached a total of approximately 40000 subjects in the 2011-2013 period.

However, if we look at the statistics of some of the main recipient countries for Portuguese emigrants, we can see that this number has been underestimated. In fact, for the same period, the statistics agency in the United Kingdom, one of the main destination countries for the latest Portuguese emigration, indicates that $21.5 \%$ of the total Portuguese emigrants over 16 have higher education qualifications.

Table 1.

School background and qualifications of Portuguese emigrants aged 15 or older, resident in OECD countries, 2000/01 and 2010/11

\begin{tabular}{|c|c|c|c|c|c|}
\hline \multirow{2}{*}{ Education level } & \multicolumn{2}{|c|}{ Census 2000/01 } & \multicolumn{2}{|c|}{ Census 2010/11 } & Growth rate \\
\hline & $\mathbf{N}$ & $\%$ & $\mathbf{N}$ & $\%$ & $\%$ \\
\hline Total & 1259829 & 100 & 1471644 & 100.0 & 16.8 \\
\hline Primary school & 847011 & 67.2 & 900915 & 61.2 & 6.4 \\
\hline Secondary school & 294899 & 23.4 & 404409 & 27.5 & 37.1 \\
\hline Higher education & 77790 & 6.2 & 145833 & 9.9 & 87.5 \\
\hline Unknown education level & 40129 & 3.2 & 20487 & 1.4 & -48.9 \\
\hline
\end{tabular}

Source: Emigration Observatory [Observatório da Emigração], "Emigração Portuguesa.

Relatório Estatístico 2014. 
Table 2 .

Number of United Kingdom immigrants born in Portugal, according to their education level, per year of arrival

\begin{tabular}{|l|c|c|c|c|c|}
\hline \multicolumn{1}{|c|}{ Education level } & $\begin{array}{c}\text { TOTAL } \\
\text { (residents } \\
\text { aged 16 } \\
\text { and older) }\end{array}$ & $\begin{array}{c}\text { Arrived } \\
\text { before } \\
1981\end{array}$ & $\begin{array}{c}\text { Arrived } \\
1981- \\
1990\end{array}$ & $\begin{array}{c}\text { Arrived } \\
1991- \\
2000\end{array}$ & $\begin{array}{c}\text { Arrived } \\
2001- \\
2011\end{array}$ \\
\hline N & $\mathbf{N}$ & $\mathbf{N}$ & $\mathbf{N}$ & $\mathbf{N}$ \\
\hline No education & 16581 & 3303 & 1931 & 4564 & 6783 \\
\hline Education level 1, 2 or 3 & 20458 & 2070 & 1587 & 6027 & 10774 \\
\hline Apprenticeship System ${ }^{4}$ & 819 & 125 & 70 & 202 & 422 \\
\hline Education level 4 and higher & 14465 & 1450 & 924 & 3134 & 8957 \\
\hline Other education level & 23676 & 1905 & 1694 & 5316 & 14761 \\
\hline \multicolumn{1}{|c|}{ TOTAL } & $\mathbf{7 5 9 9 9}$ & $\mathbf{8 8 5 3}$ & $\mathbf{6 2 0 6}$ & $\mathbf{1 9 2 4 3}$ & $\mathbf{4 1 6 9 7}$ \\
\hline TOTAL - Europe & $\mathbf{2 4 9 2 7 8 9}$ & $\mathbf{6 6 0 8 2 8}$ & $\mathbf{1 7 5 5 4 4}$ & $\mathbf{3 4 6 1 4 4}$ & $\mathbf{1 3 1 0 2 7 3}$ \\
\hline TOTAL - All categories & $\mathbf{6 9 1 0 5 9 5}$ & $\mathbf{1 8 3 6 3 5 9}$ & $\mathbf{6 5 2 6 6 5}$ & $\mathbf{1 1 8 3 3 2 8}$ & $\mathbf{3 2 3 8 2 4 3}$ \\
\hline
\end{tabular}

Source: Office for National Statistics, UK. Data for the geographic area of England and Wales.

\subsection{What is the demographic profile (gender and age) of qualified emigration?}

Considering a sample of 1011 respondents, women (54.2\%) slightly outnumber men. This is a change in the Portuguese traditionally male-dominant emigration profile and certainly the result of a greater presence of women in higher education and, consequently, in qualified jobs.

In terms of age, the sample is predominantly young (only $10.4 \%$ are over 39 years old). This can be justified by an extended juvenile period and delayed transition - into adult life, stable employment, destination family, own house -, but is additionally linked with easier access to transnational mobility networks and the difficulties experienced in finding a position in the Portuguese labour market that is compatible with the acquired qualifications (around 65\% hold at least a Masters, particularly in the areas of Mathematics and Computer Studies, followed by Engineering and Social Science).

${ }^{4}$ This level corresponds to a form of vocational training where students receive training in a training centre and a company.

5 This level corresponds to Bachelor's degree, Masters, $\mathrm{PhD}$ or other higher education degrees. 
Figure 1.

Demographic characterisation of the respondents: gender and age (\%)

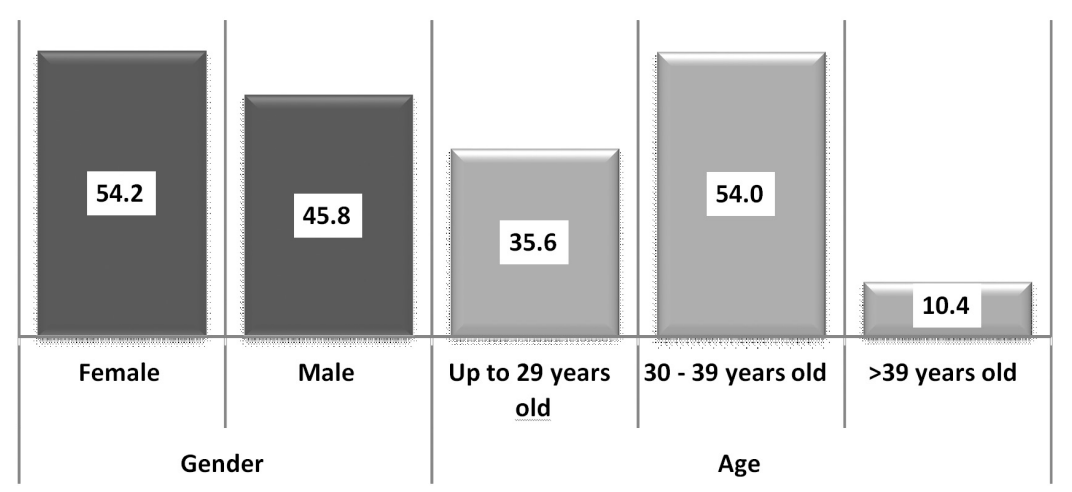

3.3. What are the academic degrees of qualified emigrants?

Figure 2.

Academic qualification of the respondents (\%)

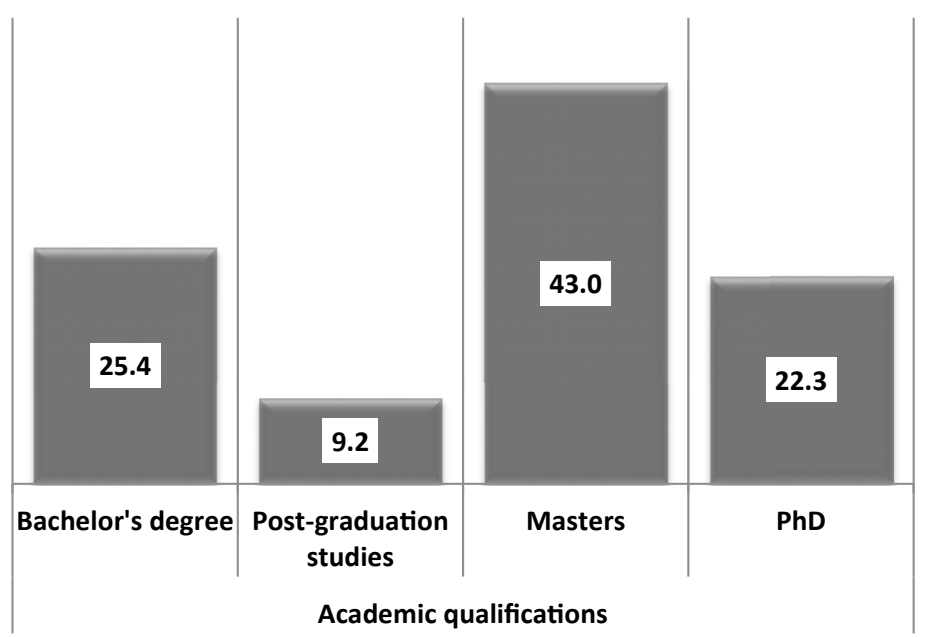

The internal composition of the sample's qualifications shows that the majority of the respondents (74.5\%) are postgraduate students - $43 \%$ have a Masters, $22.3 \%$ are Ph.D. and 9.2\% finished a postgraduate course -, while the remaining $25.4 \%$ only have a Bachelor's degree.

Subjects with Masters and Ph.D. qualifications are clearly overrepresented in the sample, if we consider that the equivalent figure is much lower in Portugal resident population up to 44 years old: 1.7\% finished their Ph.D., 11.4\% finished 
a Masters and $86.9 \%$ hold a Bachelor's degree. The trend seen in this sample suggests that the holders of higher and more specialised academic degrees account now for a bigger percentage of the qualified emigration in the latest years.

In 2014 , only $16.5 \%$ of the Portuguese population aged 15 or older had at least a Bachelor's degree. In the age group between 25 and 34, the age group of a large part of our sample, that percentage increases to $28 \%$, according to OECD data for 2012.

Hence, we are in the presence of a group of young people and young adults who have fully profited from the late school democratisation processes in Portugal and from the systematic implementation of a R\&D public system.

\subsection{What was the year of the last emigration period?}

Figure 3.

Year of the last departure from Portugal (\%)

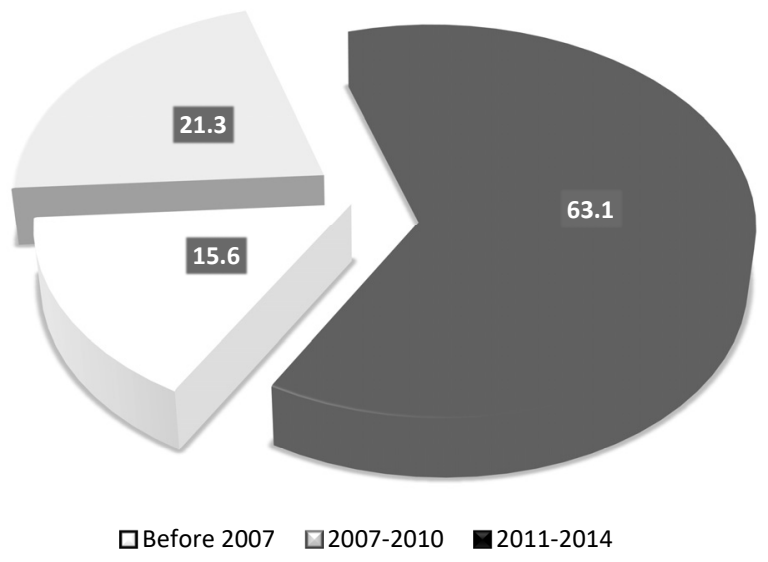

Around 4/5 of the sample left Portugal at or after the onset of the crisis, as only $15.6 \%$ left the country before 2007 . It is known that the impacts of such an intense economic context are not immediately absorbed. However, the number of departures shows beyond any doubt that 2008 was the big trigger: more than 20 thousand emigrants against a mere 7890 in the previous year (Pordata).

\subsection{What's the current country of residence?}

Looking into the current country of residence, we find that the United Kingdom $(26.7 \%)$ as well as other countries in Central Europe (Germany, France and Belgium) are the major recipient countries. However, a part of the sample was living in Portugal when they answered the questionnaire, a situation that may either 
mean they have successfully returned to Portugal (after credentials, experiences and social capital have been gained abroad) or that a transition is under way to other destinations.

\section{Figure 4.}

Current country of residence (\%)

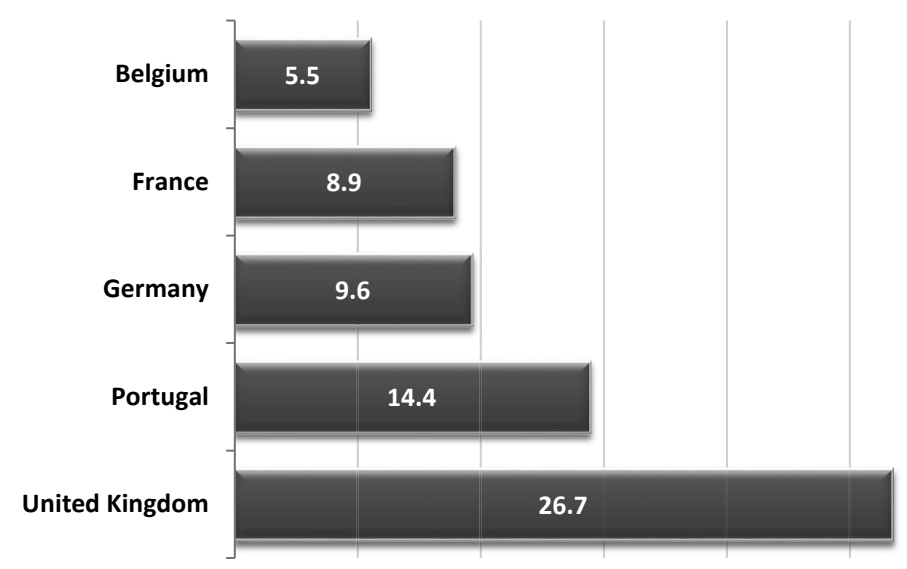

\subsection{What's the employment situation, before and after migration? What's the net monthly income, before and after migration?}

Similarly, departure from Portugal is seen to have a notorious effect on employment: only 3.8\% are unemployed at the destination country, whereas in Portugal the percentage was over $36 \%$, an approximate value that is consistent with unemployment rates for these age groups.

Figure 5.

Employment situation before and after migration (\%)

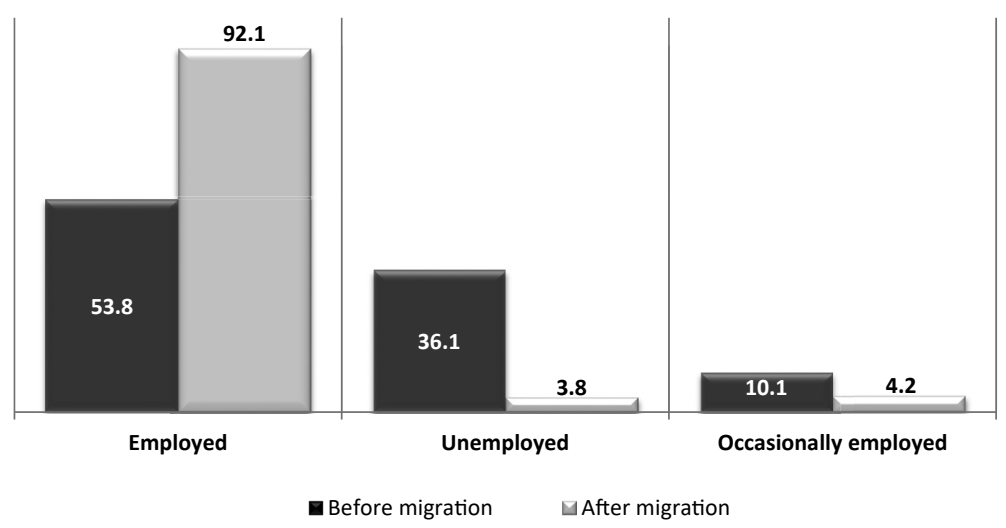


Figure 6.

Net monthly income before and after migration (\%)

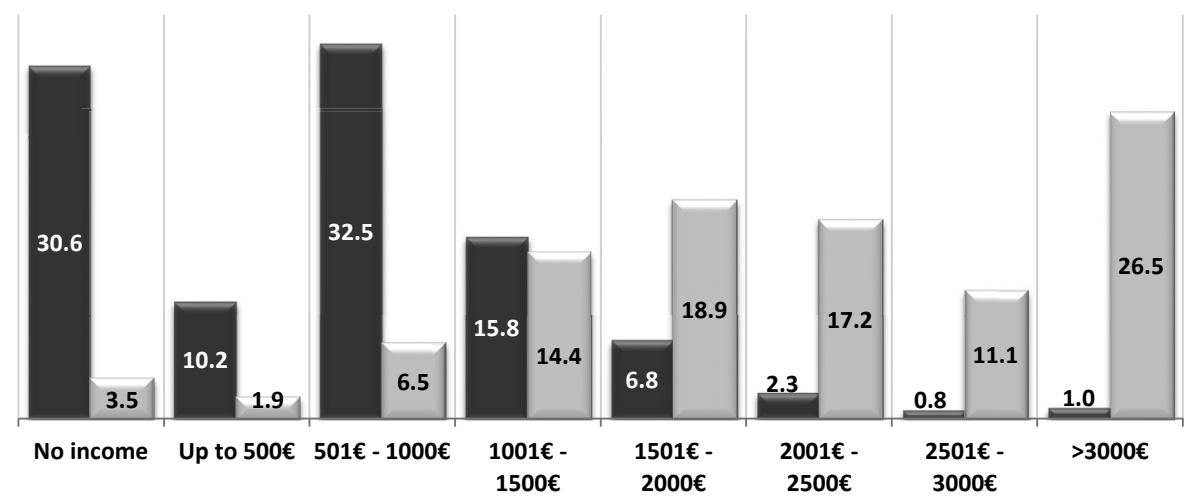

Before migration

$\square$ After migration

An important difference is also found in net monthly income: before departure, more than $70 \%$ earned less than 1000 euros, whereas, at the destination country, over $50 \%$ earn more than 2000 euros and 26.5\% have a remuneration over 3000 euros.

\subsection{What's the scientific area of initial study and highest qualification?}

Figure 7.

Scientific area of initial study and highest qualification (\%)

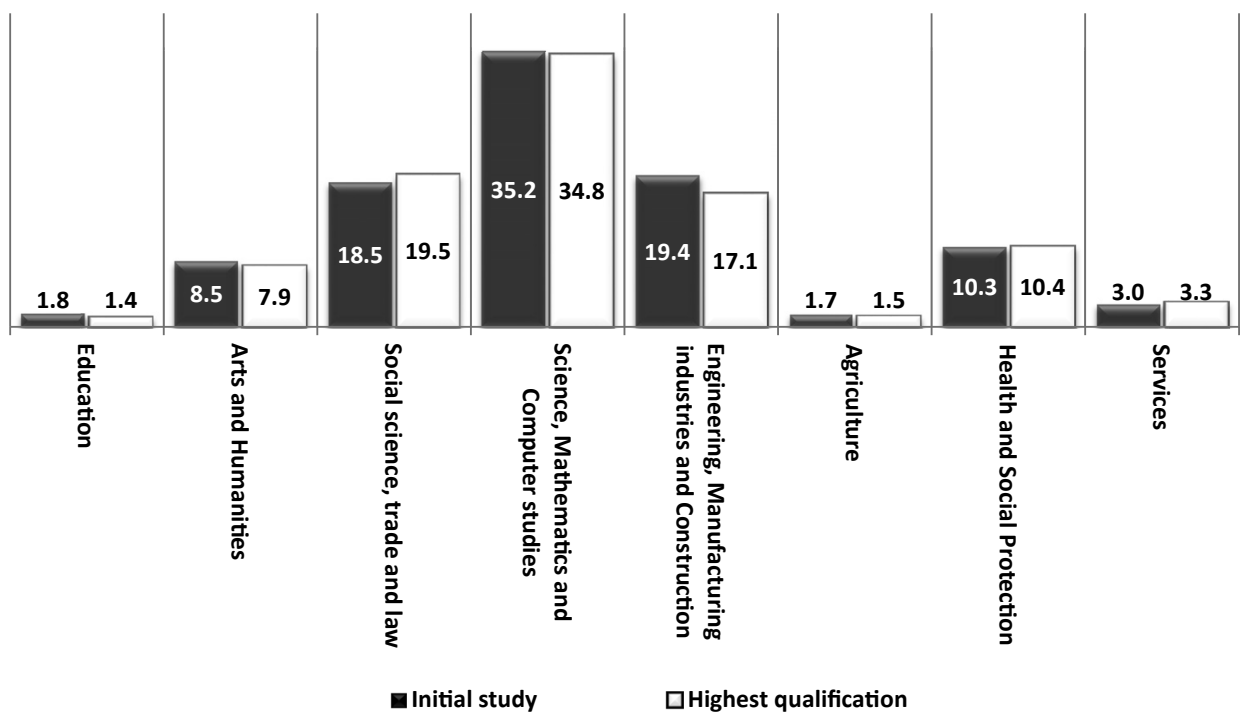


The respondents' initial area of study and the area of their highest qualification are often the same, with greater concentration in science, mathematics and computer studies (about 1/3), followed by social science, trade and law and, with similar numbers, engineering, manufacturing industries and construction. Therefore, there are no academic reskilling processes, but rather logic of continuity, with the subjects' trend to further their initial areas of study.

\subsection{What's the relationship between job and academic qualifications?}

Figure 8. Relationship between job and academic qualifications before and after migration (\%)

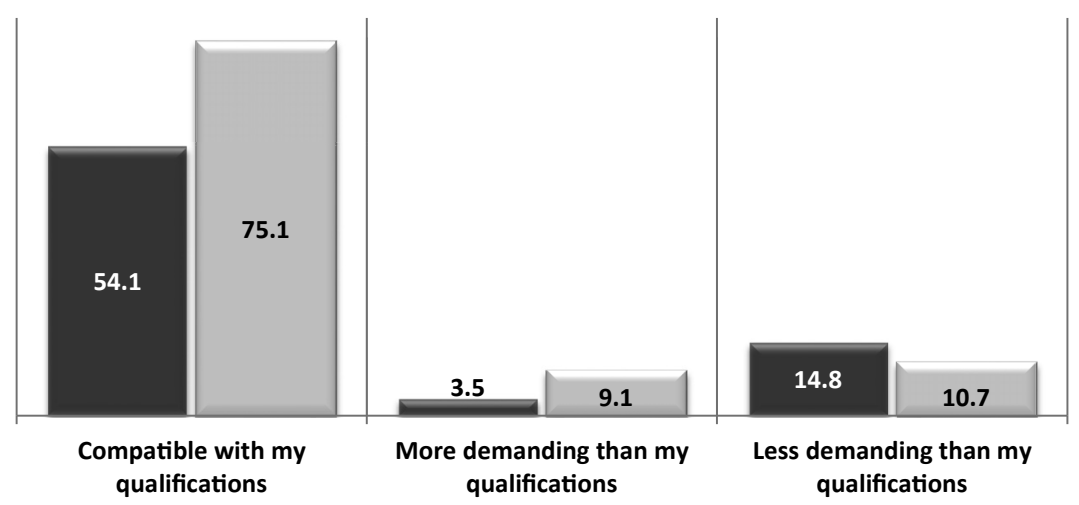

Before migration $\square$ After migration

Considering that most respondents had jobs compatible with their academic qualifications, even before they migrated, the obvious conclusion is that the formal recognition of skills and organisational resources in Portugal wasn't clearly matched with the remuneration levels, let alone with career advancement opportunities.

An increase is also seen in the numbers of those who claim that their job at the destination country exceeds their academic qualifications. The perception of being underemployed is reduced, which might be related with greater career and training opportunities.

\subsection{What are the reasons to migrate?}

The decision to migrate is mainly driven by professional and economic reasons: the pursuit of a career where the subjects feel professionally fulfilled was pointed out by $95.4 \%$ of the respondents as the main reason that made them migrate. However, wages, together with unemployment or underemployment, also seem to strongly influence the decision to leave (80.6\%). The fact that $46.2 \%$ of the sample 
was once unemployed or underemployed help us understand the relative weight of this reason. Although emotional reasons are relatively important, both family reunification and the existence of friendship networks at the destination countries clearly rank second in the hierarchy of the emigration driving motives.

Reasons to migrate (\%)

Figure 9.

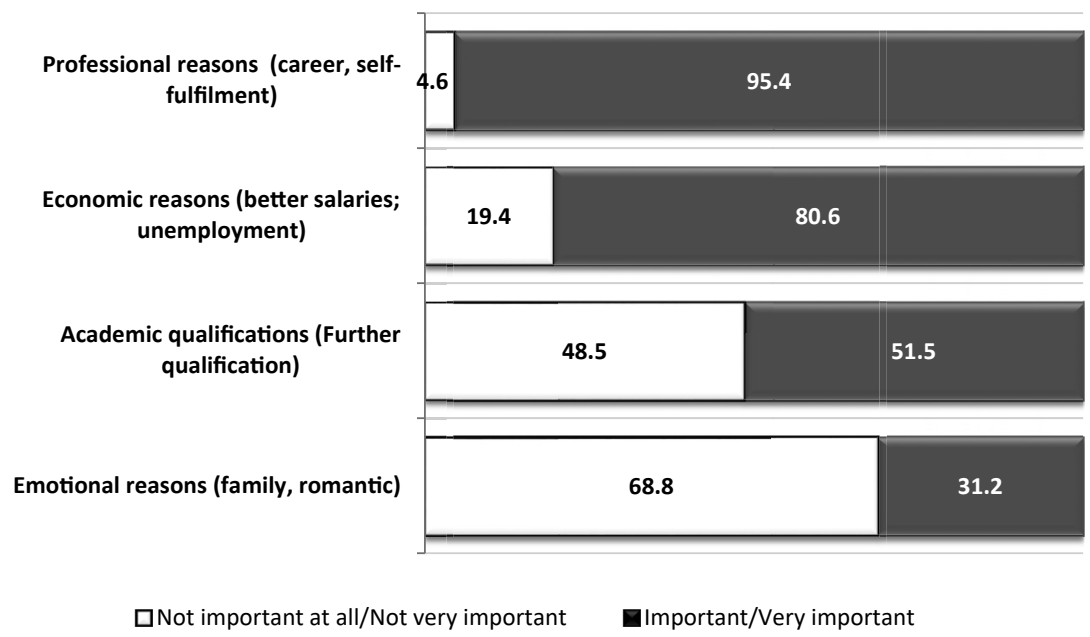

\subsubsection{Professional factors}

Figure 10.

Professional indicators (\%)

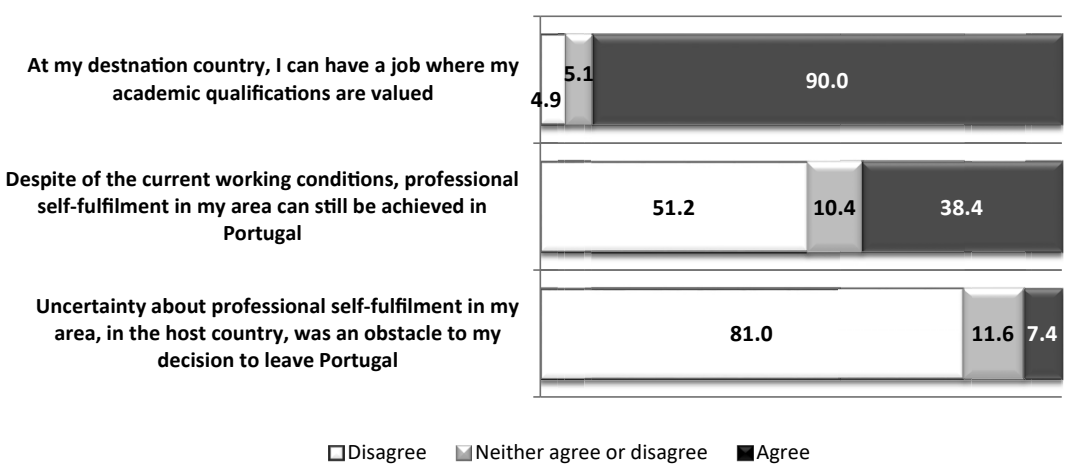

Looking closely at the professional reasons that base the decision to migrate, we see that having academic qualifications that are highly valued at the destination country is the main pull factor ( $90 \%$ of agreement), supported by the subjects' claim that it isn't possible to achieve professional fulfilment in Portugal. 


\subsubsection{Economic factors}

The breaking down of some economic indicators shows their relative impact on the decision to migrate: firstly, the economic crisis seen as a push factor; then the inadequacy of remuneration in the country of origin, closely followed by dissatisfaction with their social and economic status in Portugal and the perception of insecurity and instability caused by reduced income. On the other hand, a perception of salary adequacy and greater availability of jobs at the destination countries stand out as the main economic indicators leading to migration.

Economic indicators (\%)

Figure 11.

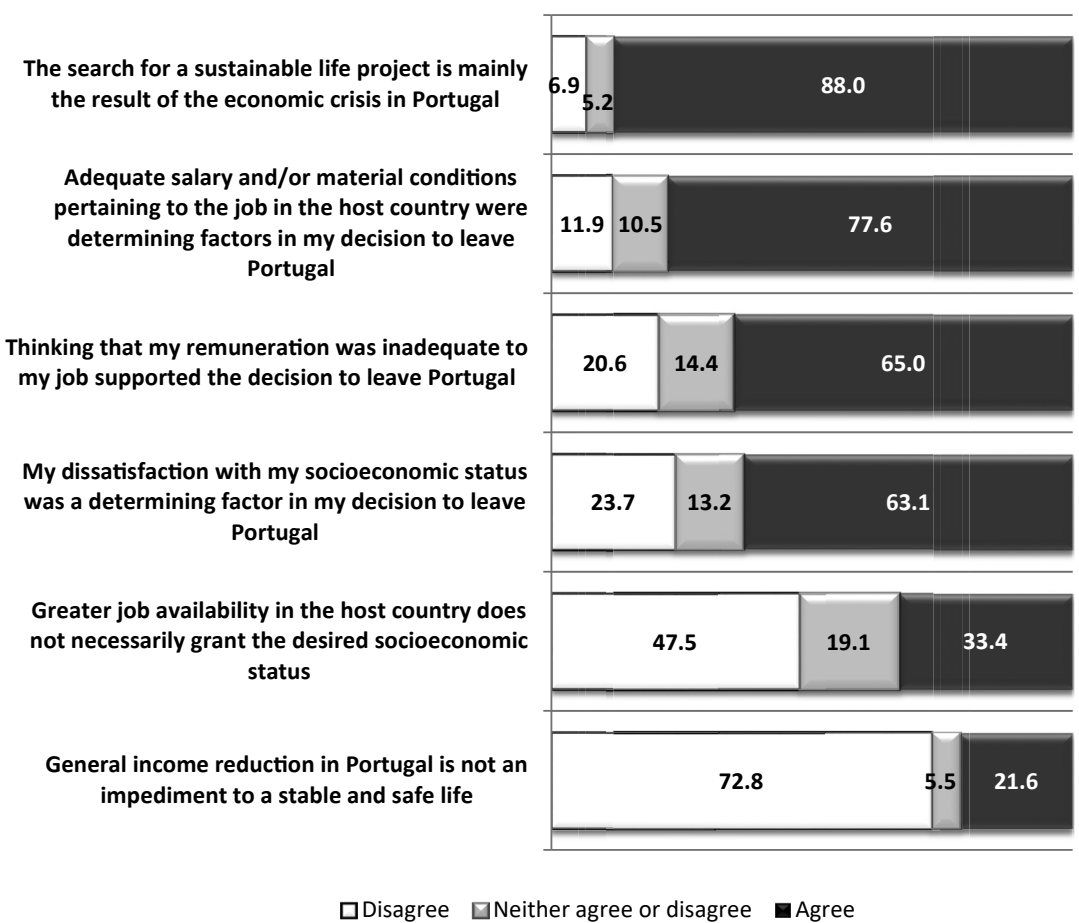

\subsubsection{Academic factors}

Among academic reasons, academic mobility experiences in other countries are identified as the most important drive, followed by the perception that their area of study is highly valued at the destination country. These indicators clearly show how academic mobility and the students' cost-benefit analysis of the experience work to turn latent brain drain into a more determined decision to migrate to central European countries. 
Academic indicators (\%)

Previous experience as a student in other countries
(e.g. ERASMUS) has encouraged my decision to leave
Portugal

The high value associated with my area of study in the host country influenced my decision to leave Portugal

The low value associated with my area of study in Portugal was a factor in my decision to leave Portugal

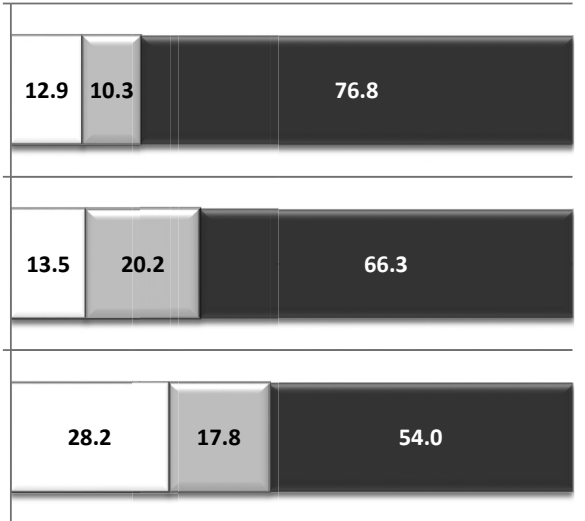

$\square$ Disagree $\square$ Neither agree or disagree $\quad$ Agree

\subsubsection{Emotional factors}

Unlike the traditional emigration processes, qualified emigrants find no significant drive to migrate in their family, friendship or emotional networks.

Emotional and friendship indicators (\%)

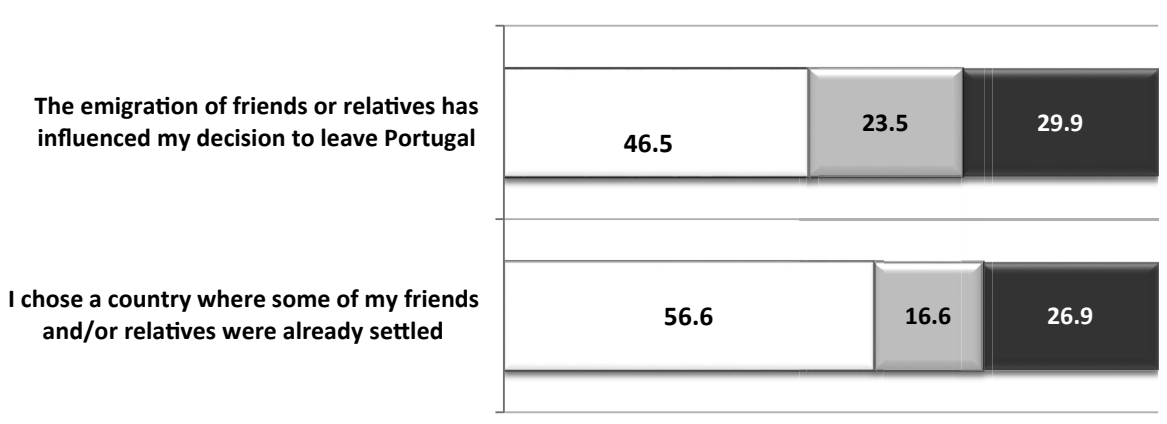

$\square$ Disagree $\square$ Neither agree or disagree $\quad$ Agree

\subsubsection{Social and political factors}

The nature of a country's social contract is important in the choice of the destination country. Subjects tend to choose countries where the social welfare state and the citizen participation are fully consolidated. On the other hand, respondents 
claim that the policies meant to limit the social welfare state in Portugal are not temporary, and that equivalent policies haven't got such serious and obvious consequences in the countries where they are currently living.

Social and political indicators (\%)

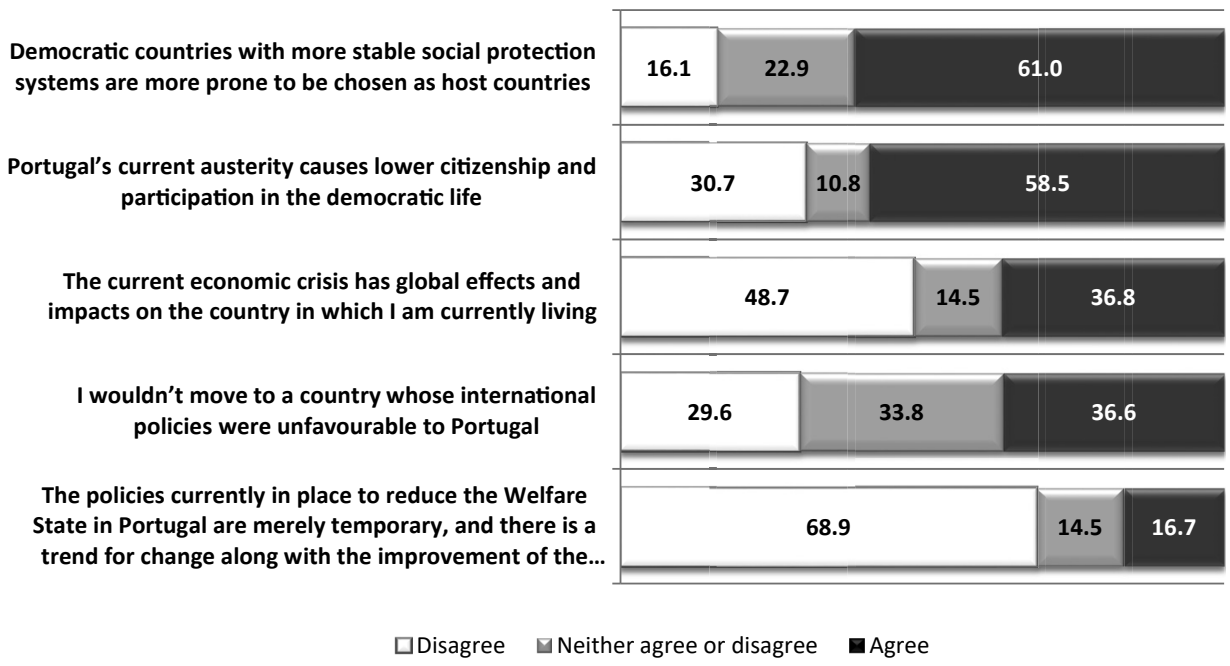

\subsection{Is the decision to migrate a short, medium or long-term decision?}

Figure 15 .

Duration of the emigration period

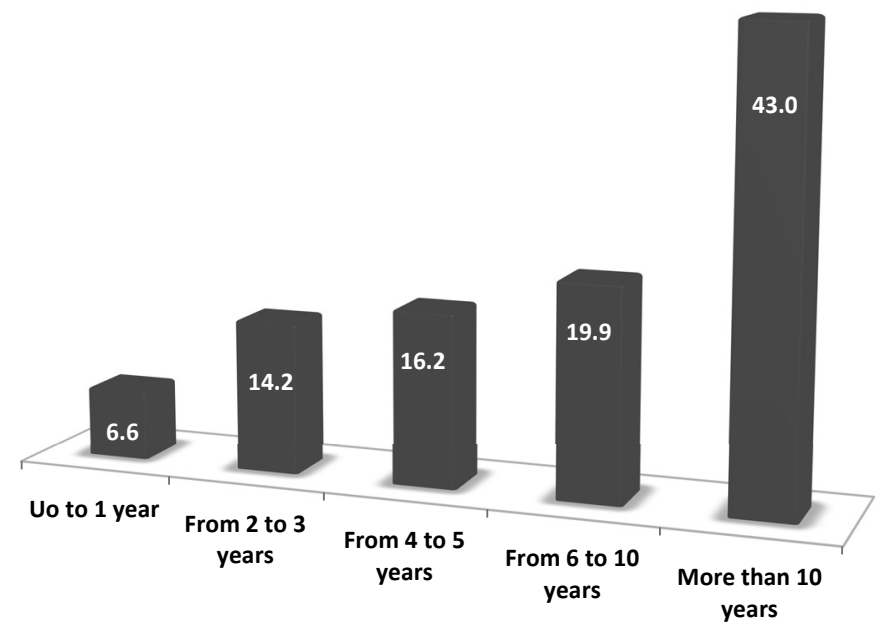


One of the aspects that may cause a loss of human capital in the country of origin is the duration of the emigration period. The majority of respondents state that mobility was initially planned as a temporary solution but their actual experience turned the initial plan into a medium $(30.4 \%)$ or long-term $(62.9 \%)^{6}$ expectation.

Most respondents accept the idea of "lifelong" emigration in the current country of residence or in other European countries (61.7\% and 68.9\% respectively).The perception of a long-lasting crisis in Portugal is also associated with the decision to work abroad for a longer period and with the expectation to return only when their professional career has been consolidated (42.9\%).

\section{Expectations for the future (\%)}

\begin{tabular}{|c|c|c|}
\hline Emigrate to another European country & 31.1 & 68.9 \\
\hline $\begin{array}{l}\text { Stay permanently in the country where I am living } \\
\text { now }\end{array}$ & 38.3 & 61.7 \\
\hline Emigrate to another non-European country & 56.6 & 43.4 \\
\hline Return permanently to Portugal & 57.1 & 42.9 \\
\hline Return temporarily to Portugal and emigrate again & 63.6 & 36.4 \\
\hline $\begin{array}{l}\text { Stay permanently in Portugal (if you are not } \\
\text { currently working/living in a foreign country) }\end{array}$ & 73.2 & 26.8 \\
\hline
\end{tabular}

\section{Conclusions}

Student mobility is now a common practice in higher education institutions. From national exploratory studies there is empirical evidence that academic mobility is an opportunity to compare between the scientific systems in the origin countries and the recipient countries, and a chance to know people (teachers, colleagues, friends) who would later be crucially important in the decision to migrate (Gomes 2015). On the other hand, being a student elsewhere, being in touch with research possibilities and having an actual liaison with the labour market in a different setting inevitably triggers comparison. Destination countries are often praised for

${ }^{6}$ Within this study, medium-term emigration includes the expectation to live out of Portugal for two to five year period. Long-term emigration includes the expectation to live out of Portugal for six or more years. 
better consistency between higher education and job opportunities, with permeable well-equipped R\&D systems that offer sustainable careers and perspectives.

This is a generation that has always lived in and known a "borderless" and free circulation Europe, where international experiences are encouraged in the academic world. For this reason, in some cases, mobility is hardly seen as emigration. Student mobility experiences as part of the Erasmus programme, among others, promote a taste for the overseas and a craving for other cultures, and contribute to establish a contact network that becomes useful when the decision is made to migrate.

However, we found that, even before their training experience abroad, respondents showed an inclination for non-linear trajectories, were open to a certain degree of improvisation, embraced mobility and cosmopolitan contact, as opposed to expecting or wishing for a rapid settling of their academic and professional careers. Surely they are part of an "adaptable generation", socialized in the assumption that fixed and taken for granted careers are no longer available, as widely conveyed by a variety of political forces. Hence, no existential issues arise, as long as "one is doing what one likes to do" and a certain standard of living and consumption can be provided for.

A striking feature in the working experiences of some qualified emigrants is their great flexibility and adaptability. Qualified emigrants are flexible in their working hours and in their job descriptions; they feature spatial flexibility and cognitive and personal adaptability to deal with a short-lived and yet challenging working setting. Even if these trajectories are, for the great part, successful and take place in segments of the labour market with some level of protection, the choice for a consistent well-structured professional career is only accessible to a part of the qualified workers.

In this universe where imposed or sought after flexibility is the rule, there are those who win, those who lose and those who resist. Among the winners, predominant life narratives are the ones that focus on vocation and professional engagement as a way to achieve self-fulfilment. Losers, on the other hand, see work as an instrument to ensure the means of living necessary to build a life project. For resistants, life is centred off work, and the expressive and reflexive dimensions of life are considered a greater good in terms of personal fulfilment.

Frequent change of jobs or job descriptions very often hinders full integration in all types of career. Though wages abroad are more attractive than in original countries, they cannot always be taken for granted. Consequently, some who take part in the new wave of qualified emigrants shape themselves to what seems to be the worker profile preferred by the contemporary flexible economy: they are permanently open to new experiences, they are capable of questioning themselves and they can adjust to short-term working experiences, even when there are few rewards. 
Spatial flexibility often brings transitory and commuter emigrants to a crossroad where it is not only a matter of changing jobs, cities or countries, but rather accepting the mobile character of life as a whole. Coming and going, being today in a native city and in a foreign city tomorrow is more than just changing places. It requires permanent cultural mediation. Notions of belonging and identity are no longer tied with a specific territory and local processes. The idea of one's own culture doesn't make sense anymore for those who have long translocal learning and working experiences. The plurality of cultures is easily accepted, but managing plurality implies multiple localisms in the majority of cases.

Whether they will return or not is the question they all ask themselves at some time of their migratory trajectory, and the answer is not always the same. For some, return is seen as something temporary or remote in time (returning for a holiday or when they retire); for others, return is only a matter of wishful thinking and depends on whether the original country can offer them the right conditions to achieve professional fulfilment. The decision to return is linked with a number of other factors, particularly lifecycle or family related. The existence of a romantic partner is key to consolidate the emigration experience and can obliterate or delay the possibility of returning in the short or medium term. On the other hand, starting a family is a factor that might promote new mobilities.

National responses to the highly skilled migration may focus on the narrowly understood national interest or perceive the mobility of highly skilled migrants as an element of free movement advantageous for both sending and receiving countries. The assumption of the research is that the dynamics of institutional reactions towards the issue of highly skilled migration is a demonstration of the transforming political cultures in the European Union. While the issue of highly skilled migration was perceived in the context of brain drain and brain gain in the previous decades, with time national responses to this type of migration reflect the changing understanding of the phenomenon as "brain circulation" and cross-fertilisation of elites. Such policies have become an important element of increasingly Europeanised political culture. The legal and institutional framework development in the sphere of migration policy plays a significant role in the consolidation of European Union. The confrontation of two perspectives - the national interest and supra-national/ European interest - is reflected in the shape of political debate and media discourse that, depending on the context, may represent both type of responses.

In the case of sending countries, political responses to highly skilled migration and brain drain are divided in the academic literature into three categories: return policies, retention policies and network policies. Return policies are institutional solutions that promote return migration and professional re-integration for highly skilled migrants. Retention policies include solutions that improve professional opportunities for highly skilled individuals in the potential sending country and create incentives to stay. They also encompass policies restricting possibilities for 
emigration of highly skilled individuals. Network policies focus on initiatives that facilitate and intensify knowledge transfer, attract investments and remittances from highly skilled nationals who emigrated, including means that promote networking and development of linkages with highly skilled nationals abroad.

In the case of destination countries, political solutions attracting highly skilled migration include i.a.: incentives for foreign students to start education in the receiving country, circulation-friendly visa regimes, facilitation of temporary movement of highly skilled migrants. They may also encompass solutions which promote students and graduates over other kinds of migration, especially favoring them over low-skilled migrants.

High skill emigration has attracted a lot of media attention in Portugal, UK and Germany. In Portugal, such emigration was seen as a national tragedy and as a significant risk for undermining recovery if the best and brightest would search for employment abroad. In receiving countries, UK and Germany in particular, such immigration was discussed in relation to the country's demographic profile and its needs to import skilled workers for its strong economy. However, such media spells must be analysed in a more recent perspective also in relation to the Brexit. We seek to fill this gap for a comparative study of the media coverage on the part of both origin and destination countries of intra-EU migration, investigating whether the topics and discursive frames used are common/different among them.

The study of politicisation of the issue of highly skilled migration should include in following researches the analysis of documents and public discourses, particularly in the UK and German cases. The case studies will allow the examination of the fundamental mechanisms of attracting/retaining/repulsing highly skilled migrants as well as dynamic patterns of educational policies and how they are responsive to a changing demographic situation.

\section{References}

Beine, M., F. Docquier, and H. Rapoport. (2003). Brain Drain and LDC's Growth: Winners and Losers. IZA Discussion Paper 819. Bonn.

Beine, M., F. Docquier, and H. Rapoport. (2008). Brain Drain and Human Capital Formation in Developing Countries: Winners and Losers. The Economic Journal, 118 (528): 631-652.

Castles, S., and M. J. Miller. (2003). Age of Migration International Population Movements in the Modern World. Basingstoke: Palgrave Macmillan.

Docquier, F., and A. Marfouk. (2007). Brain Drain in Developing Countries. World Bank Economic Review, 21 (2): 193-218.

Docquier, F., O. Faye, and P. Pestieau. (2008). Is Migration a Good Substitute for Education Subsidies? Journal of Development Economics, 86 (2): 263-276.

Emigration Observatory [Observatório da Emigração]. (2014). Emigração Portuguesa. Relatório Estatístico. Lisboa: Observatório da Emigração.

Faini, R. (2003). Is the Brain Drain an Unmitigated Blessing? WIDER Discussion Paper $n^{\circ}$ 2003/64. Helsinki: United Nations University, WIDER. 
Forster, N. (2000). The Myth of the International Manager. International Journal of Human Resource Management, 11 (1): 126-142.

Gomes, R. M., ed. (2015a). Fuga de cérebros. Retratos da emigração portuguesa qualificada. Lisboa: Bertrand.

Gomes, R. M., ed. (2015b). Entre a periferia e o centro. Percursos de emigrantes portugueses qualificados. Coimbra: Imprensa da Universidade de Coimbra.

Hamilton, K. (2003). Migration and Development: Blind Fact and Hand-to-Find Facts. Washington, DC: Migration Policy Institute.

Haque, N., and S. J. Kim. (1995). Human Capital Flight: Impact of Migration on Income and Growth. IMF Staff Paper, 42 (3): 577-607.

Heuer, N. (2011). The Effect of Occupation-Specific Brain Drain on Human Capital. Working Papers in Economic and Finance, 7. Tubingen: University of Tubingen.

Johnson, J.M., and M. Regets. (1998). International Mobility of Scientists and Engineers to the US. Brain Drain or Brain Circulation? NSF Issue Brief 98-316. Arlington.

https://www.nsf.gov/statistics/issuebrf/sib98316.htm

Krueger, R. (1998). Developing questions for focus groups. Thousand Oaks: Sage.

Mahroum, S. (2000). Highly Skilled Globetrotters. Mapping the International Migration of Human Capital. $R$ \& D Management, 30 (1): 23-31.

Meyer, J.-B. (2001). Network Approach versus Brain Drain: Lessons from the Diaspora. International Migration, 5: 91-110.

Miyagiwa, K. (1991). Scale Economies in Education and the Brain Drain Problem. International Economic Review, 32: 743-759.

Mountford, A. (1997). Can a Brain Drain be Good for Growth in the Source Economy? Journal of Development Economics, 53 (2): 287-303.

Olesen, H. (2002). Migration, Return and Development: An Institutional Perspective. International Migration, 40 (4): 125-151.

Pizarro, J.M. (2005). Globalizados, pero restringidos. Una visión latinoamericana del mercado global de recursos humanos calificados. Santiago de Chile: Centro Latinoamericano y Caribeno de Demografia.

Rosenbaum, J. E., T. Kariya, R. Settersen, and T. Maier. (1990). Market and Network Theories of the Transition from High-School to Work: Their Application to Industrial Societies. Annual Review of Sociology, 16: 263-299.

Straubhaar, T. (2000). International Mobility of the Highly Skilled: Brain Drain, Brain Gain or Brain Exchange? Discussion Paper no 88. Hamburg: Hamburgisches Welt-Wirtschafts-Archiv. 